ULTRAFINE INTERDENTAL BRUSHES

Oral healthcare specialists Curaprox have devised a range of ultrafine interdental brushes that match each interproximal space. The soft brushes are gentle on the most delicate of gums and are available in a variety of lengths and thicknesses, ensuring perfect compatibility for every patient.

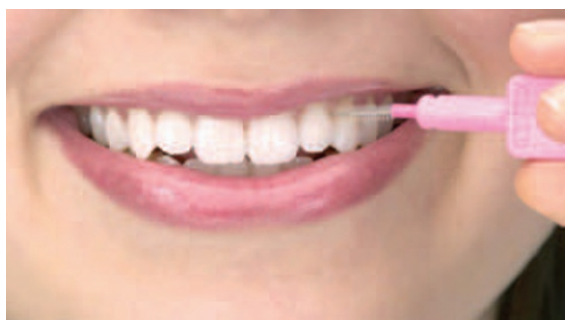

Studies looking at gum disease have concluded that an effective oral healthcare routine could help patients to avoid experiencing stillbirths or developing breast cancer. Such findings corroborate the widely accepted belief amongst healthcare professionals of a systemic link between gum disease and chronic disorders found beyond the oral cavity.

Interproximal cleaning provides an excellent solution, which patients can effortlessly incorporate into a daily oral healthcare routine. Interdental brushes are much easier to employ than dental floss, successfully cleaning debris away from areas that are difficult to reach.

Reader response number 57

professionals to incorporate their existing logo and stationery from which they can manage all day-today changes prior to printing.

The mydentalpress platform will save dental professionals time, money and work.

Reader response number 58

\section{OPT FOR ROTATION-OSCILLATION}

A recent report from the Cochrane Collaboration confirmed that "power brushes with an oscillating-rotating action reduced plaque and gingivitis more than those with a side to side action in the short term'. The term 'side to side' action refers to the action marketed and known as sonic.

In an earlier review in 2005,

Cochrane stated that brushes with a rotation-oscillating action removed plaque and reduced gingivitis more effectively than manual brushes in the short term and reduced gingivitis scores in studies over three months (www.cochrane.org).

With an array of electric toothbrush designs available, dental professionals may find it difficult to determine which options provide the most effective outcomes for their patients. Oral-B pioneered oscillating-rotating technology. Since their introduction in 1991, the company has published over 90 clinical papers and abstracts demonstrating the superior efficacy of this mode of action in an electric toothbrush. The company's flagship model is the Triumph 5000 with SmartGuide, which incorporates many complianceenhancing features. Brushing frequency, time and technique can all affect the performance of a toothbrush. The Triumph 5000 will help your patients brush better. Using it they're on average five times more likely to adhere to the recommended two minutes twice a day and are less likely to use excessive brushing force. Reader response number 59

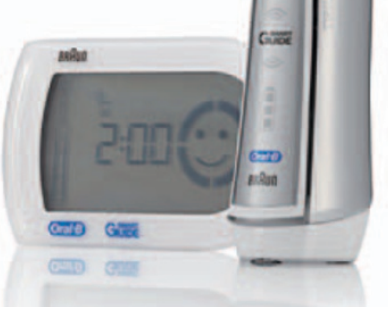

